\title{
Optimization of Laser Transmission Joining Process Parameters on Joint Strength of PET and 316 L Stainless Steel Joint Using Response Surface Methodology
}

\author{
Shashi Prakash Dwivedi and Satpal Sharma \\ Gautam Buddha University, Greater Noida, Gautam Buddha Nagar, Uttar Pradesh 201310, India \\ Correspondence should be addressed to Shashi Prakash Dwivedi; shashi_gla47@rediffmail.com
}

Received 8 July 2014; Accepted 8 September 2014; Published 29 September 2014

Academic Editor: Jose M. Guisan

Copyright (C) 2014 S. P. Dwivedi and S. Sharma. This is an open access article distributed under the Creative Commons Attribution License, which permits unrestricted use, distribution, and reproduction in any medium, provided the original work is properly cited.

\begin{abstract}
The objective of the present work is to study the effects of laser power, joining speed, and stand-off distance on the joint strength of PET and $316 \mathrm{~L}$ stainless steel joint. The process parameters were optimized using response methodology for achieving good joint strength. The central composite design (CCD) has been utilized to plan the experiments and response surface methodology (RSM) is employed to develop mathematical model between laser transmission joining parameters and desired response (joint strength). From the ANOVA (analysis of variance), it was concluded that laser power is contributing more and it is followed by joining speed and stand-off distance. In the range of process parameters, the result shows that laser power increases and joint strength increases. Whereas joining speed increases, joint strength increases. The joint strength increases with the increase of the stand-off distance until it reaches the center value; the joint strength then starts to decrease with the increase of stand-off distance beyond the center limit. Optimum values of laser power, joining speed, and stand-off distance were found to be $18 \mathrm{watt}, 100 \mathrm{~mm} / \mathrm{min}$, and $2 \mathrm{~mm}$ to get the maximum joint strength (predicted: $88.48 \mathrm{MPa}$ ). There was approximately $3.37 \%$ error in the experimental and modeled results of joint strength.
\end{abstract}

\section{Introduction}

Laser transmission joining has various advantages over conventional plastic joining techniques, for example, no contact, high joining speed, accuracy, flexibility, small heat affected zone, and so forth. Laser transmission joining technology has extensively promising applications in the fields of the microfluidics, microelectromechanical systems, and biomedicine $[1,2]$. During laser transmission welding of overlap connections laser radiation transmits through the upper thermoplastic part and is absorbed by a lower material. Heat is developed in the laser absorbing part, which melts the thermoplastic locally. Due to heat conduction, the laser transparent part melts locally too. Thermoplastic materials are laser radiation absorbing, when the material contains, for example, carbon black, absorbing additives, and pigments or when the materials are reinforced with carbon fibers [3]. There is a continuously growing interest in the joining of dissimilar materials in manufacturing industries. Joining of PET to $316 \mathrm{~L}$ stainless steel is found in a number of industrial applications [4].

The advantages of laser transmission joining are as follows: (a) exact control of the energy deposition in the joining area; (b) minimization of the heat affected zone; (c) complex weld and bond geometries; (d) selective joining; (e) singlestep process; (f) short cycle times [5].

In the present work, response surface methodology was used to investigate and optimize the input process parameters, namely, laser power, joining speed, and stand-off distance, which influence the joint strength. The materials used in this work were PET films and $316 \mathrm{~L}$ stainless steel sheets.

\section{Materials and Methods}

2.1. Selection of the Material. In the present work, PET films and $316 \mathrm{~L}$ stainless steel are selected for the laser transmission 
TABLE 1: Chemical composition and mechanical properties of $316 \mathrm{~L}$ stainless steel (\% wt.).

\begin{tabular}{|c|c|c|c|c|c|c|c|c|c|c|c|}
\hline \multicolumn{10}{|c|}{ Chemical composition (\% wt.) } & \multicolumn{2}{|c|}{ Mechanical properties } \\
\hline $\mathrm{C}$ & $\mathrm{Mn}$ & $\mathrm{P}$ & S & $\mathrm{Si}$ & $\mathrm{Cr}$ & $\mathrm{Ni}$ & Mo & $\mathrm{N}$ & $\mathrm{Fe}$ & $\begin{array}{l}\text { UTS } \\
(\mathrm{MPa})\end{array}$ & $\begin{array}{l}\text { Hardness } \\
\text { (Rockwell) }\end{array}$ \\
\hline 0.03 & 2 & 0.045 & 0.03 & 0.7 & 16 & 12 & 2.8 & 0.1 & Balance & 558 & B79 \\
\hline
\end{tabular}

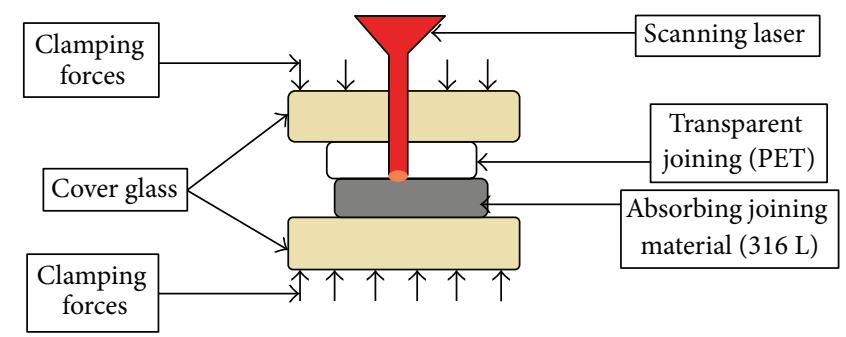

FIGURE 1: Schematic diagram of laser transmission joining process.

joining process. $316 \mathrm{~L}$ stainless steel is an austenitic chromium nickel stainless steel containing molybdenum. This addition increases corrosion resistance, improves resistance to pitting from chloride ion solutions, and provides increased strength at elevated temperatures $[6,7]$. The chemical composition and mechanical properties of $316 \mathrm{~L}$ stainless steel are shown in Table 1 [8].

PET is unreinforced, semicrystalline thermoplastic polyester. Its excellent wear resistance, high flexural modulus, superior dimensional stability, and low coefficient of friction make it a multipurpose material for designing mechanical and electromechanical parts. Because PET has no centerline porosity, the possibility of fluid absorption and leakage is virtually eliminated [9].

2.2. Laser Transmission Joining Process. PET sheets with dimensions of $35 \mathrm{~mm} \times 15 \mathrm{~mm} \times 0.15 \mathrm{~mm}$ and $316 \mathrm{~L}$ stainless steel sheets with dimensions of $35 \mathrm{~mm} \times 15 \mathrm{~mm} \times 0.1 \mathrm{~mm}$ were prepared as samples. Argon gas is used for cleaning the interaction zone and cleaning and cooling the PET surface to reduce polymer dissociation and distortion.

In the laser transmission joining of PET films and $316 \mathrm{~L}$ stainless steel joining (Figure 1), PET and $316 \mathrm{~L}$ stainless steel are brought into contact prior to welding. Then, the laser beam passes through the PET films and is absorbed at the weld interface. With good contact between the parts at the interface, heat is conducted into the parts, causing melting at both surfaces. When predetermined amount of melt has been generated, heating is terminated and the melt solidifies to generate a weld.

2.3. Selection of Laser Transmission Joining Process Parameters and Their Levels. In the pilot run investigation, for the selection of ranges of laser power, joining speed, and stand-off distance, a number of trials were examined. On the basis of pilot run investigation, laser transmission process parameters with their ranges are shown in Table 2.

After the selection of range of process parameters from the pilot run investigation, the experiment is designed, based
TABLE 2: Process parameters with their ranges.

\begin{tabular}{lcc}
\hline S. number & Input parameters & Range \\
\hline 1 & Power (watt) & $14-18$ \\
2 & Joining speed $(\mathrm{mm} / \mathrm{min})$. & $100-200$ \\
3 & Stand-off distance $(\mathrm{mm})$ & $1-3$ \\
\hline
\end{tabular}

on central composite design (CCD). Design of Expert is used to perform statistical analysis, to develop mathematical models, and to optimize the process parameters. Lasertransmission joining was carried out randomly as per design matrix shown in Table 3. Corresponding measured joint strength under different runs is also presented in Table 3.

2.4. Response Surface Methodology. Response surface methodology comprises statistical experimental designs, regression modeling techniques, and optimization methods. Central composite design (CCD) is an experimental design, helpful in response surface methodology, for building a second order (quadratic) model for the response variable without needing to use a complete three-level factorial experiment $[10,11]$.

Objective of the present work is to focus on the second strategy: statistical modeling to build up a suitable approximating model between the response $y$ (joint strength) and independent variables, $\xi_{1}, \xi_{2}, \ldots, \xi_{k}$.

In general, the relationship is

$$
y=f\left(\xi_{1}, \xi_{2}, \ldots, \xi_{k}\right)+\varepsilon .
$$

If it has a normal distribution with mean zero and variance $\sigma^{2}$, then it may be written as

$$
\begin{aligned}
E(y) & =\eta=E\left[f\left(\xi_{1}, \xi_{2}, \ldots, \xi_{k}\right)\right]+E(\varepsilon) \\
& =f\left(\xi_{1}, \xi_{2}, \ldots, \xi_{k}\right),
\end{aligned}
$$

where variables $\xi_{1}, \xi_{2}, \ldots, \xi_{k}$ are generally the natural variables. 
TABLE 3: Design matrix and experimental results.

\begin{tabular}{lccccc}
\hline Standard order & Run order & Power (watt) & Joining speed $(\mathrm{mm} / \mathrm{min}$.) & Stand-off distance $(\mathrm{mm})$ & Joint strength $(\mathrm{MPa})$ \\
\hline 18 & 1 & 16 & 150 & 2 & 89.15 \\
1 & 2 & 14 & 100 & 1 & 69.9 \\
3 & 3 & 14 & 200 & 1 & 60.59 \\
8 & 4 & 18 & 200 & 3 & 79.65 \\
9 & 5 & 12.64 & 150 & 2 & 68.18 \\
15 & 6 & 16 & 150 & 2 & 88.31 \\
6 & 7 & 18 & 100 & 3 & 97.1 \\
17 & 8 & 16 & 150 & 2 & 88.12 \\
19 & 9 & 16 & 150 & 2 & 88.71 \\
14 & 10 & 16 & 150 & 3.68 & 69.76 \\
16 & 11 & 16 & 150 & 2 & 88 \\
4 & 12 & 18 & 200 & 1 & 80.14 \\
13 & 13 & 16 & 150 & 3 & 62.2 \\
5 & 14 & 14 & 100 & 2 & 77.84 \\
12 & 15 & 16 & 234.09 & 1 & 70.9 \\
2 & 16 & 18 & 100 & 2 & 92.35 \\
20 & 17 & 16 & 150 & 3 & 88.71 \\
7 & 18 & 14 & 200 & 2 & 62.75 \\
11 & 19 & 16 & 65.91 & 2 & 94.1 \\
10 & 20 & 19.36 & 150 & 32 & 100.36 \\
\hline
\end{tabular}

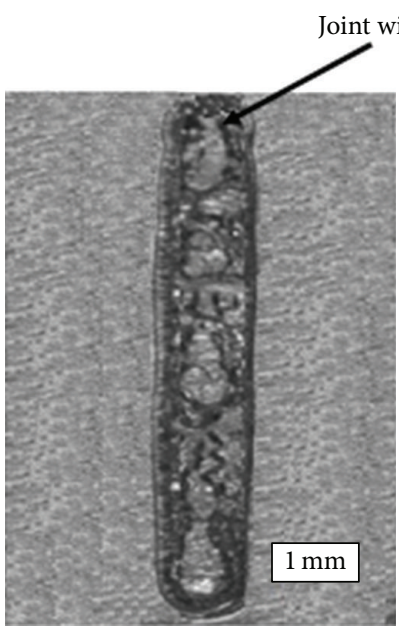

(a)

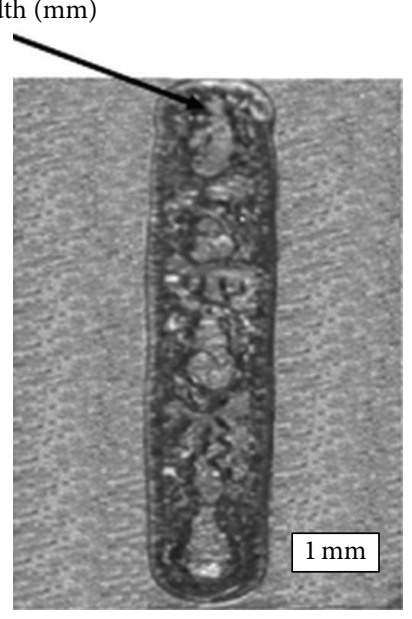

(b)

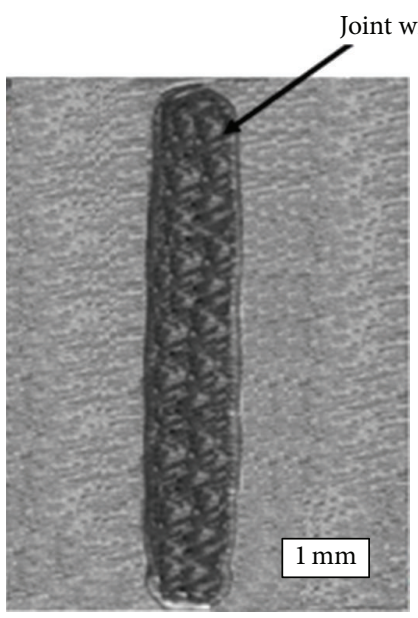

(c)

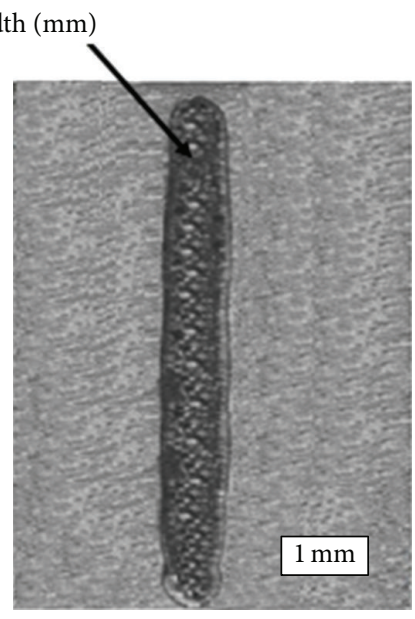

(d)

FIGURE 2: Macrostructure of joint seam width of $316 \mathrm{~L}$ stainless steel and PET joint.

In terms of the coded variables, the response function (2) is written as

$$
\eta=f\left(X_{1}, X_{2}, \ldots, X_{k}\right) .
$$

In the case of two independent variables, the first-order model in terms of the coded variables is written as

$$
\eta=\beta_{o}+\beta_{1} X_{1}+\beta_{2} X_{2}
$$

Equation (4) is called main effects model, since it includes just the main effects of the two variables $X_{1}$ and $X_{2}$. If there is an interaction between these variables, it can be added to the model easily as follows $[12,13]$ :

$$
\eta=\beta_{o}+\beta_{1} X_{1}+\beta_{2} X_{2}+\beta_{12} X_{1} X_{2}
$$

\section{Results and Discussion}

3.1. Macrostructure Appearance. Figure 2 shows the macrostructure of joint seam width of $316 \mathrm{~L}$ stainless steel and PET joint used for tensile testing. In the range of process parameters, good bonds are achieved with minimum joint seam width. The macrostructure of four samples, which were 


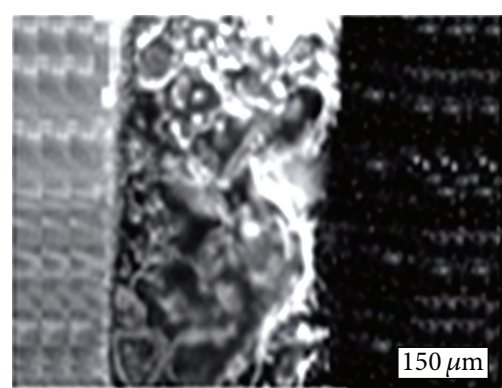

(a)

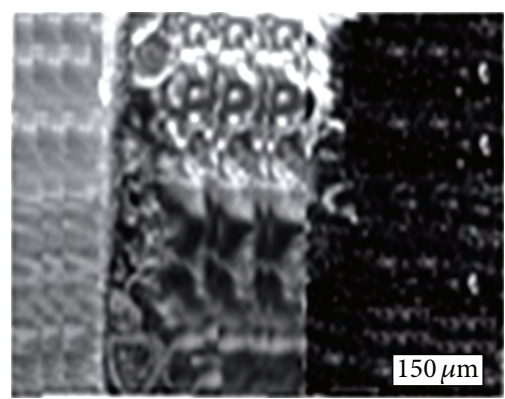

(d)

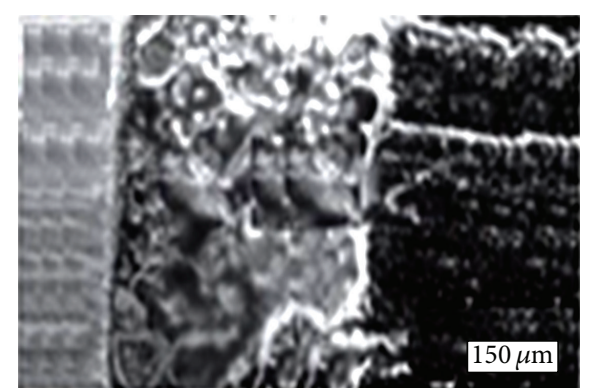

(b)

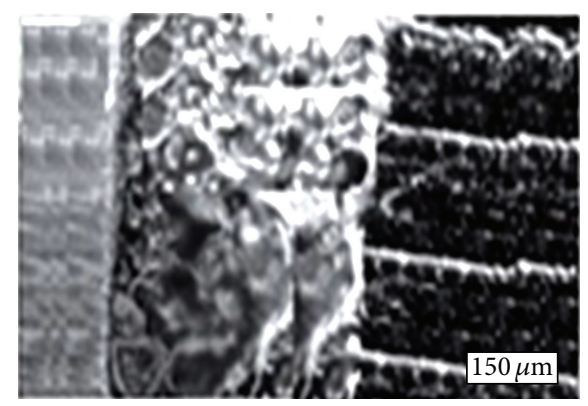

(e)

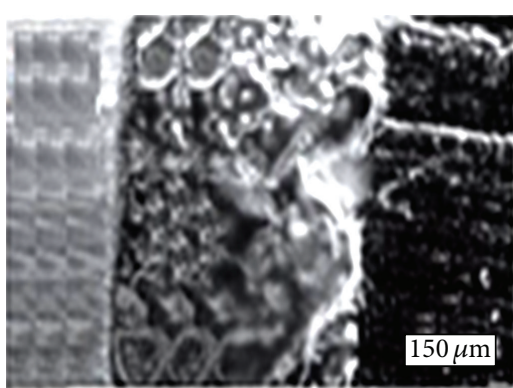

(c)

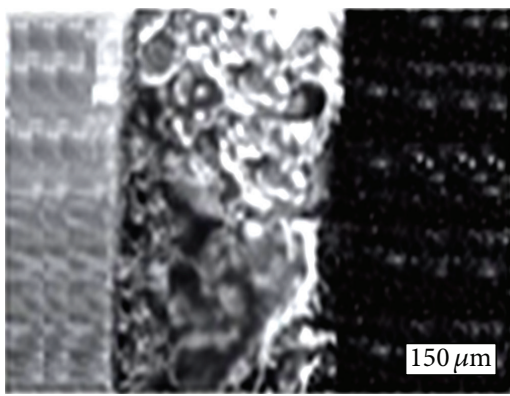

(f)

FIgURE 3: Microstructure of joint seam width of $316 \mathrm{~L}$ stainless steel and PET joint.

fabricated in the range of process parameters (Table 3), is shown in Figure 2 and demonstrates that when the joint samples were prepared in the range of process parameters, the PET have been degenerated or burnt at the joint area.

3.2. Microstructure Appearance. Figure 3 presents the microstructure of the PET and $316 \mathrm{~L}$ stainless steel joint and the heat affected zone. Low cavity and better bubble formation can be seen in Figure 3. Cavity formation is related to PET burning, charring, or vaporization which may weaken the joint strength, while rapid development of bubbles increases the built pressure resulting joint strength also increases.

3.3. Development of Mathematical Model of Joint Strength. Optimization of parameters like laser power, joining speed, and stand-off distance was made on laser transmission joining process. Central composite design (CCD) experiments using response surface methodology were proved to be an optimal tool for optimization of joint strength.

Analysis of variance (ANOVA) table has been used to review the test for significance of regression model, test for significance for model coefficient, and test for "lack-of-fit." Significant model terms were recognized at 95\% significance level. Goodness of fit was examined from $R^{2}$ (coefficient of correlation) and C.V. (coefficient of variation) with the intention to ensure the reliability and precision of the model. ANOVA table for the joint strength is shown in Table 4. The Probability $>F$ for the model (Table 4 ) is less than 0.05 which shows that the model is significant, which is desirable as it demonstrates that the terms in the model have a significant effect on the response (joint strength). In this case $A$ (laser power), $B$ (joining speed), $C$ (stand-off distance), $A B, A C$, $B C, A^{2}, B^{2}$, and $C^{2}$ are significant model terms. The ANOVA table for quadratic model pointed out that the model was significant at $P \leq 0.0001$, and its lack-of-fit, 2.27, was not significant. In this case $A, B, C, A B, A C, B C, A^{2}, B^{2}$, and $C^{2}$ are significant model terms. The lack-of-fit is said to be insignificant. The $R^{2}$ value (0.9989) was high, close to one, which was desirable.

The predicted $R^{2}$ value (0.9936) was in acceptable agreement with the adjusted $R^{2}(0.9980)$. Adequate precision measures signal to noise ratio was calculated by dividing the difference between the maximum predicted joint strength (response) and the minimum predicted joint strength (response) by the average standard deviation of all predicted responses. Ratios greater than 4 are desirable. In this case the value was 103.941 which was well above 4 , which pointed out adequate signals to use this model to navigate the design space. PRESS (prediction error sum of squares) is a measure of how well the model for the experiment is expected to predict the responses in new experiments. Small values of PRESS (17.60) are desirable.

The regression coefficients of the second order equations have been developed by using the experimental data. The regression equation for the joint strength as a function of laser power, joining speed, and stand-off distance is given in the following:

$$
\begin{aligned}
\text { Joint strength }= & -144.84943+17.47871 * \text { Power } \\
& +0.26288 * \text { Joining speed } \\
& +43.28067 * \text { Stand-off distance }
\end{aligned}
$$


TABLE 4: Analysis of variance (ANOVA) for joint strength.

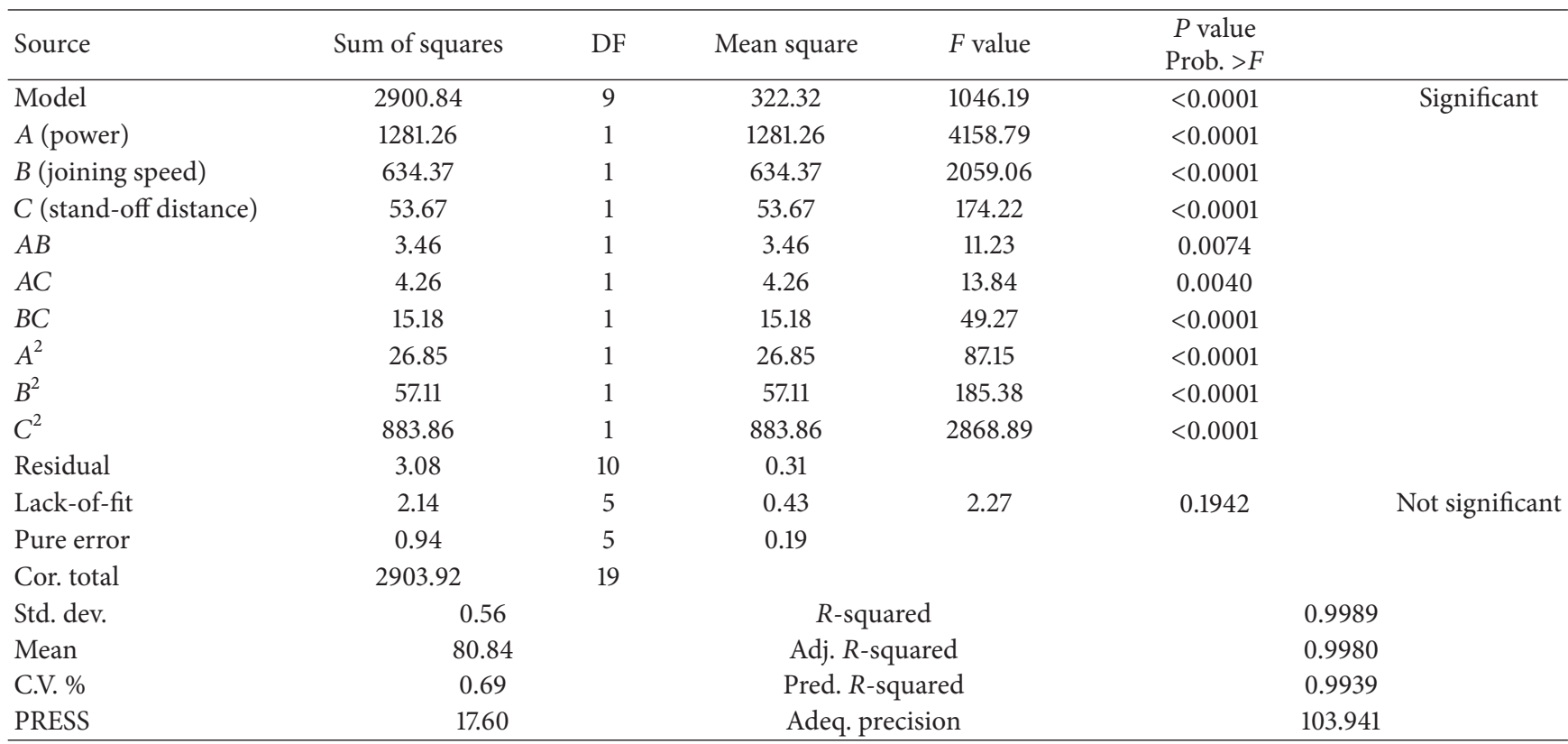

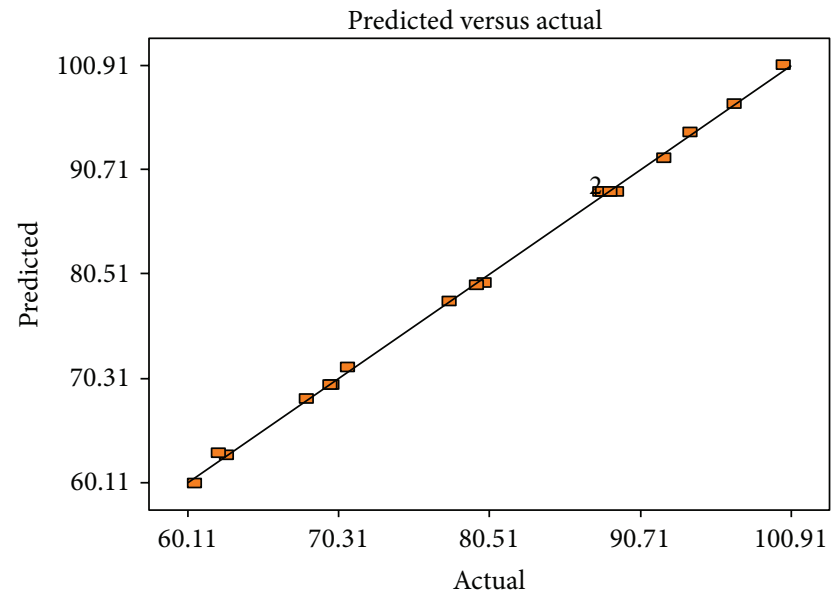

FIGURE 4: Correlation between the predicted and actual values.

$$
\begin{aligned}
& -0.34123 * \text { Power }^{2} \\
& -7.96289 E-004 * \text { Joining speed }^{2} \\
& -7.83143 * \text { Stand-off distance } \\
& -6.57500 E-003 * \text { Power } * \text { Joining speed } \\
& -0.36500 * \text { Power } * \text { Stand-off distance } \\
& -0.027550 * \text { Joining speed } \\
& * \text { Stand-off distance. }
\end{aligned}
$$

The model adequacy is inspected by evaluating the residuals (difference between observed and fitted value of response). If the model is acceptable, the residuals should be

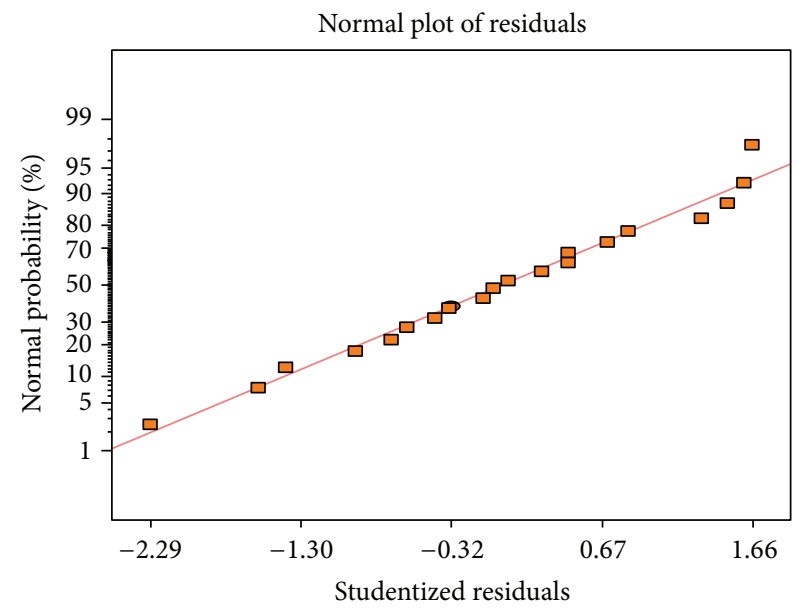

FIgURE 5: Normal probabilities of residuals.

without structure; that is, they should contain no noticeable pattern (Figure 4).

The model inadequacy can be further checked by study of normal probability plot of residuals. If the error allocation is normal, this plot will approximate a straight line. The normal probability plot of residuals is shown in Figure 5. From this plot, it can be concluded that the error distribution is normal and model can be used for further investigation.

Desirability is an objective function which varies from zero (outside of the limits) to one (at the goal). The numerical optimization identifies a point that maximizes the desirability function. Desirability value of one that corresponded to the maximum value of joint strength in the given range of laser transmission process parameters has been considered in the present investigation. When laser power, joining speed, 


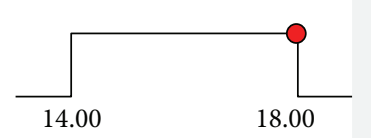

Power $=17.99$

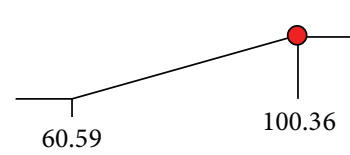

Joint strength $=100.531$

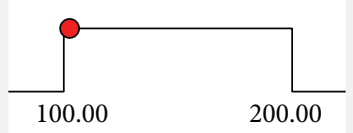

Joining speed $=102.28$

Desirability $=1.000$

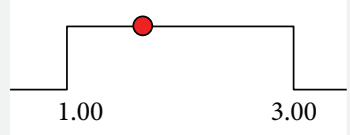

Stand-off distance $=1.69$

FIGURE 6: Ramp function graph for maximum joint strength with desirability one.

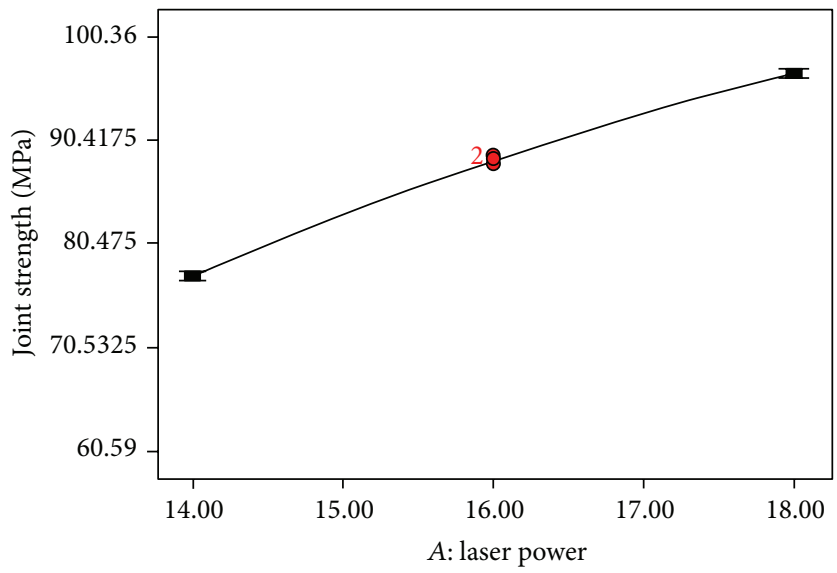

(a)

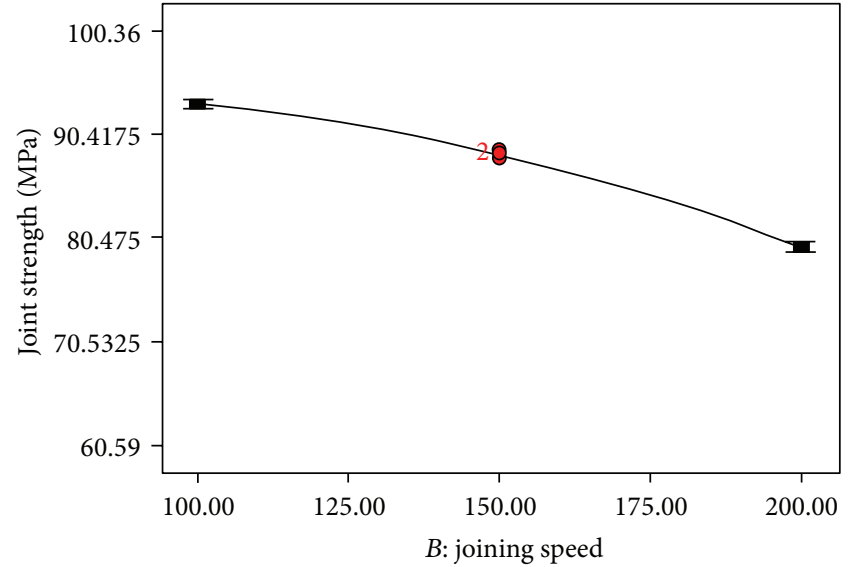

(b)

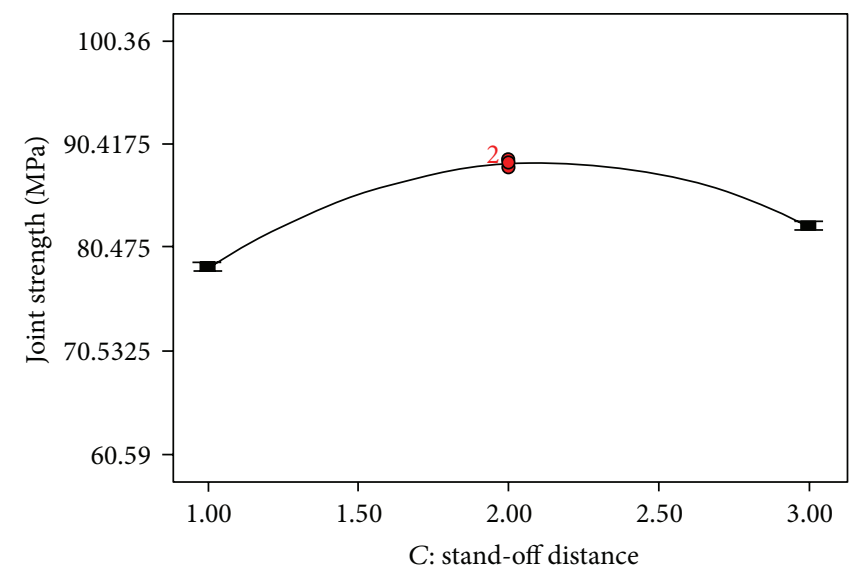

(c)

FIGURE 7: Single factor effect of laser power, joining speed, and stand-off distance on joint strength.

and stand-off distance were 17.99 watt, $102.28 \mathrm{~mm} / \mathrm{min}$, and $1.69 \mathrm{~mm}$, then the optimum value of joint strength was 100.531 MPa. Ramp function graph for laser transmission joining of PET and $316 \mathrm{~L}$ stainless steel for maximum joint strength is given in Figure 6. It exposed what shall the value of parameters be to obtain maximum value of joint strength (100.531) for different laser transmission joining process parameters with desirability one.

3.4. Single Factor Effect of Process Parameters on Joint Strength. Figure 7 illustrates the single factor effect of laser power, joining speed, and stand-off distance on joint strength of PET and 


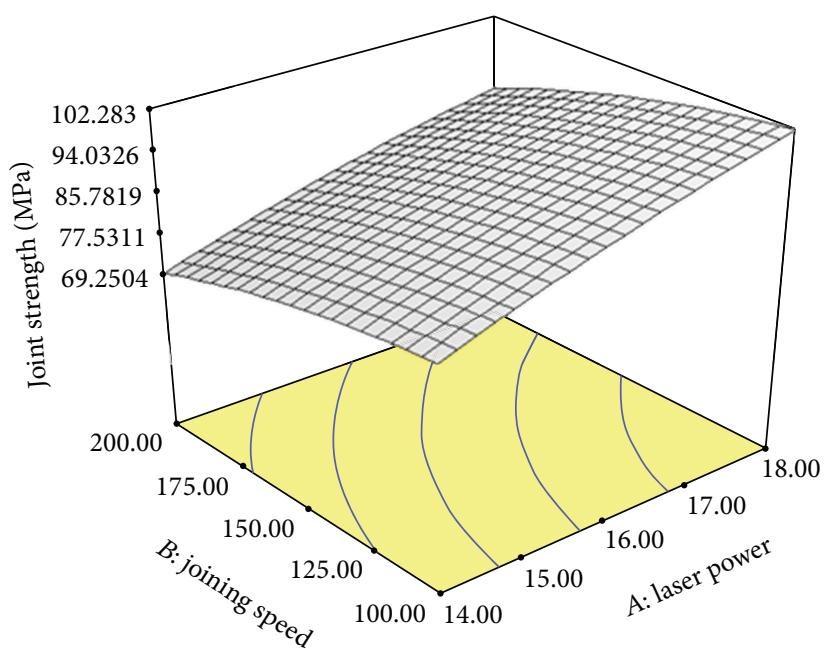

(a)

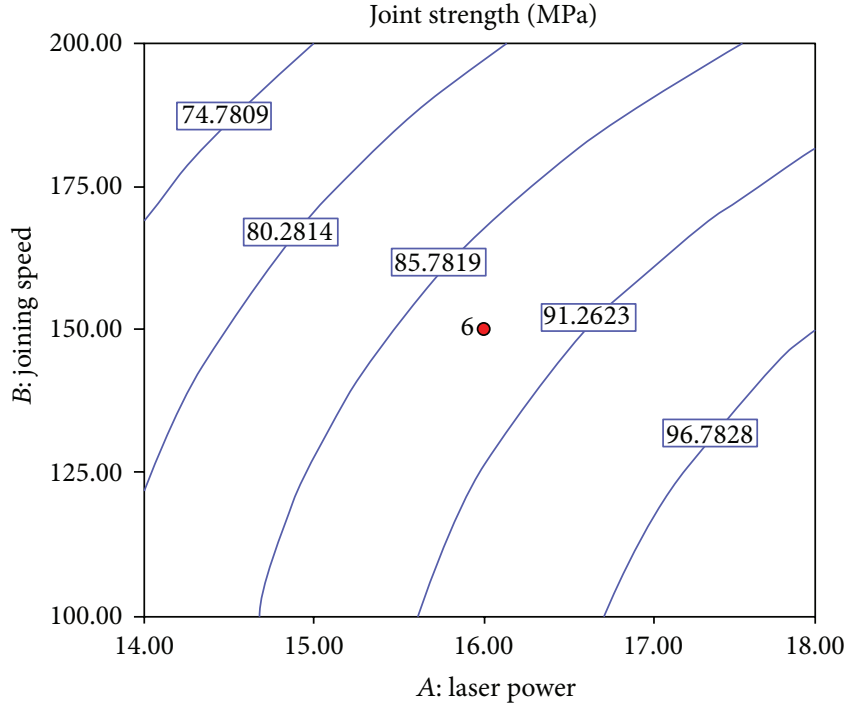

(b)

FIGURE 8: Interaction effect of laser power and joining speed on the joint strength. (a) 3D interaction; (b) the contour plot.

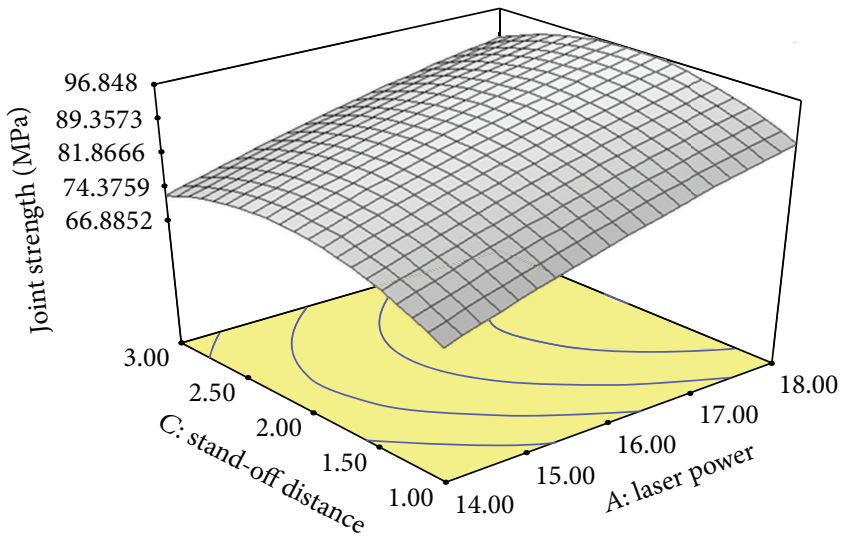

(a)

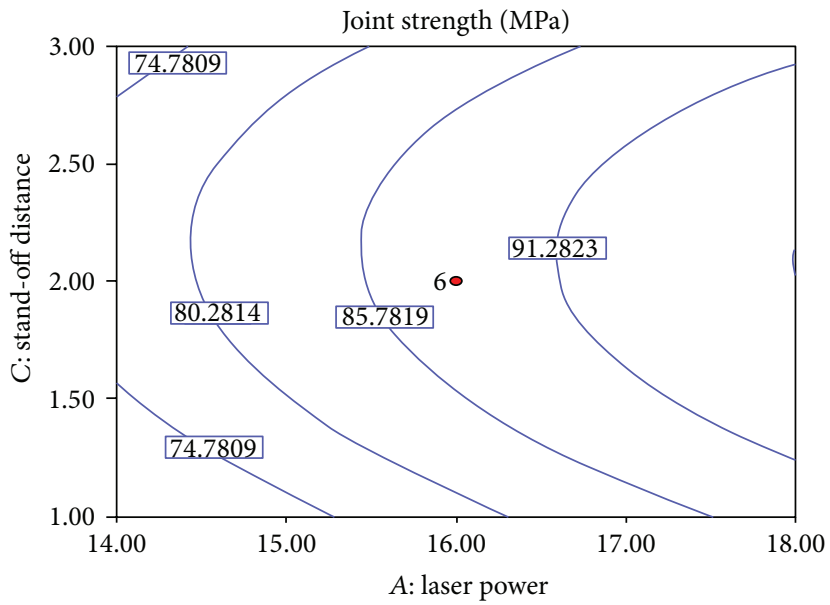

(b)

FIGURE 9: Interaction effect of laser power and stand-off distance on the joint strength. (a) 3D interaction; (b) the contour plot.

$316 \mathrm{~L}$ stainless steel joint in the range of process parameters is discussed as follows.

3.4.1. Single Factor Effect of Laser Power on Joint Strength. From Figure 7(a), it can be noticed that the joint strength increases with the increase of laser power. In the laser transmission joining process, it was observed that when laser power increased, the heat input also increased, resulting in the increase of weld seam width. When weld seam width increased, melting area of joint increased, resulting also in joint strength increase.

3.4.2. Single Factor Effect of Joining Speed on Joint Strength. As shown in Figure 7(b), joining speed increases from minimum to maximum limit and the joint strength decreases. Because a higher joining speed reduces the irradiation time, leading to low-heat input to the weld zone, the joint strength decreases.

3.4.3. Single Factor Effect of Stand-Off Distance on Joint Strength. As shown in Figure 7(c), joint strength increases with the increase in stand-off distance. Figure 7(c) illustrates that the radiation area rises with the increment of the standoff distance, resulting in the increase of the joint strength until it reaches its center value $(2 \mathrm{~mm})$ of stand-off distance; the joint strength then starts to decline with the increment of stand-off distance above the center limit as an outcome of lower power density [14].

3.5. Interaction Effect of Process Parameters on Joint Strength. Figures 8 to 10 display the interaction effect of laser power, joining speed, and stand-off distance on joint strength. 
TABLE 5: Confirmation experiment table.

\begin{tabular}{|c|c|c|c|c|c|}
\hline Responses & Experiment number & $\begin{array}{l}\text { Experiment value } \\
\qquad(\mathrm{MPa})\end{array}$ & $\begin{array}{c}\text { Average of } \\
\text { experimental value } \\
(\mathrm{MPa})\end{array}$ & $\begin{array}{l}\text { Predicted value } \\
\text { (MPa) }\end{array}$ & Percentage variation \\
\hline \multirow{3}{*}{ Joint strength } & 1 & 87.6 & \multirow{3}{*}{91.56} & \multirow{3}{*}{88.48} & \multirow{3}{*}{$3.37 \%$} \\
\hline & 2 & 94.5 & & & \\
\hline & 3 & 92.6 & & & \\
\hline
\end{tabular}

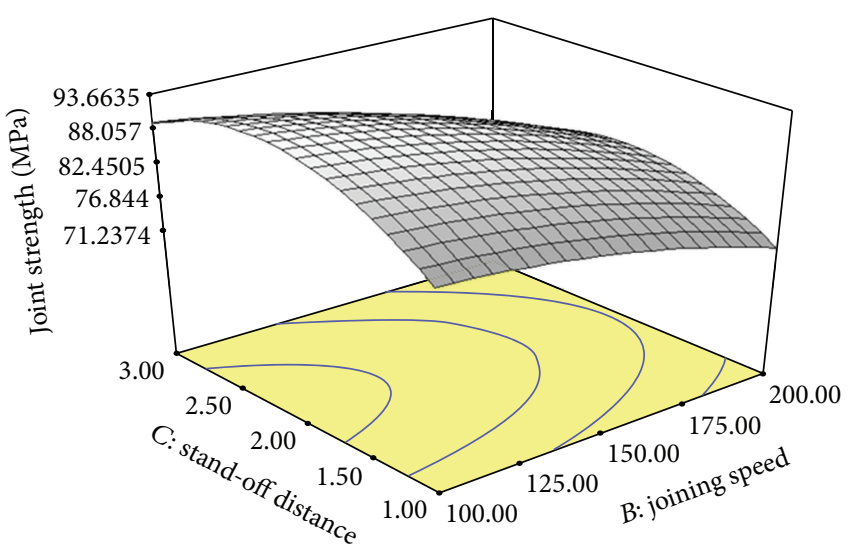

(a)

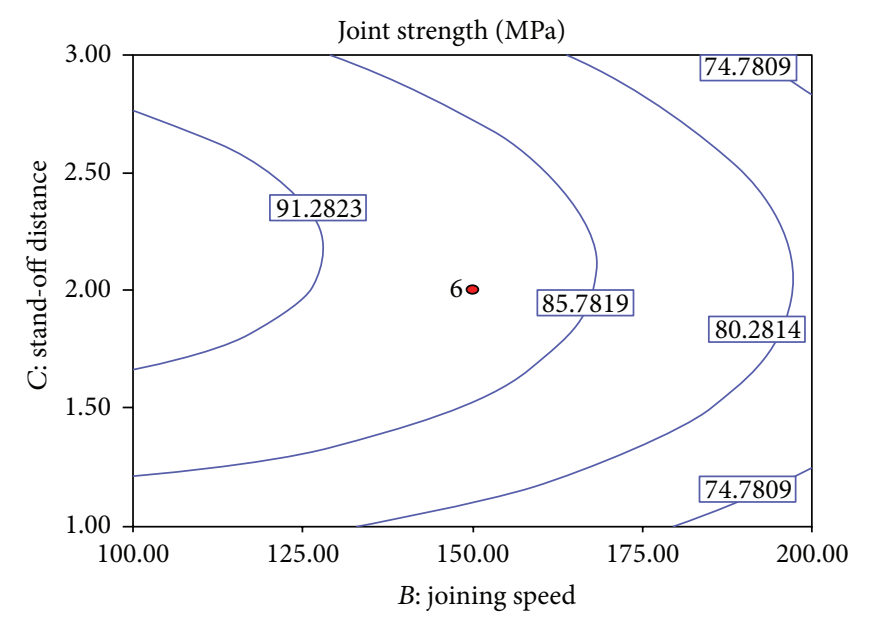

(b)

FIGURE 10: Interaction effect of joining speed and stand-off distance on the joint strength. (a) 3D interaction; (b) the contour plot.

3.5.1. Interaction Effect of Laser Power and Joining Speed on the Joint Strength. Figures 8(a) and 8(b) present the interaction effect of the laser power and joining speed on the joint strength. It is noticeable that the joint strength leans to rise with high laser power and low joining speed. During the joining of PET and $316 \mathrm{~L}$ stainless steel, higher laser power and lower joining speed increased laser energy density, resulting in joint strength increase.

3.5.2. Interaction Effect of Laser Power and Stand-Off Distance on the Joint Strength. Influence of laser power and stand-off distance is displayed in Figures 9(a) and 9(b). From Figure 9, it can be noticed that as the laser power increases and standoff distance increases up to the center value, the joint strength leans to increase. If stand-off distance further increases, joint strength decreases.

3.5.3. Interaction Effect of Joining Speed and Stand-Off Distance on the Joint Strength. Figures 10(a) and 10(b) show the effect of joining speed and stand-off distance on the joint strength. From Figure 10, it can be concluded that when the stand-off distance is higher, increasing the joining speed decreases the joint strength, while increasing the joining speed at lower stand-off distance increases the joint strength [14].

3.6. Confirmation Experiments. In order to validate the predicted joint strength $(88.48 \mathrm{MPa})$, at the optimum process parameters (laser power of 18 watt, joining speed of $100 \mathrm{~mm} /$ min, and stand-off distance of $2 \mathrm{~mm}$ ), experimental data were compared with data obtained by point prediction (predicted value). The results tabulated in Table 5 show that experimental data (average of three samples) and predicted data closely correlate with each other. This shows that there is only $3.37 \%$ error in the experimental and modeled results. Hence, the developed model can be effectively used in the process parameters range to predict the joint strength of PET films and $316 \mathrm{~L}$ stainless steel joint in laser transmission welding.

\section{Conclusions}

The following conclusions can be drawn from the analysis.

(1) Laser transmission joining can be adapted favorably for the joint between PET films and $316 \mathrm{~L}$ stainless steel.

(2) Microstructure of the welded joint revealed good bond between PET films and 316 L stainless steel and very less amount of cavity and vaporization observed.

(3) Within the laser transmission joining process parameters range, as the laser power increases, the joint strength also increases, while the joint strength decreases with increased joining speed. On the other hand, the joint strength increases with the increase of the stand-off distance until it reaches the center value; 
the strength then starts to decrease with the increase of stand-off distance beyond the center limit.

(4) The maximum value of joint strength with desirability one was obtained: $100.531 \mathrm{MPa}$ at laser power of 17.99 watt, joining speed of $102.28 \mathrm{~mm} / \mathrm{min}$, and stand-off distance of $1.69 \mathrm{~mm}$.

(5) Within the laser transmission joining process parameters the optimum parameters for joint strength were found to be higher laser power (18 watt), lower joining speed $(100 \mathrm{~mm} / \mathrm{min})$, and mid value of stand-off distance $(2 \mathrm{~mm})$. The predicted value of joint strength was found to be $88.48 \mathrm{MPa}$ at $95 \%$ confidence interval. There is only $3.37 \%$ error in the experimental and modeled results.

\section{Conflict of Interests}

The authors declare that there is no conflict of interests regarding the publication of this paper.

\section{References}

[1] X. Wang, C. Zhang, P. Li et al., "Modeling and optimization of joint quality for laser transmission joint of thermoplastic using an artificial neural network and a genetic algorithm," Optics and Lasers in Engineering, vol. 50, no. 11, pp. 1522-1532, 2012.

[2] F. Sari, W. M. Hoffmann, E. Haberstroh, and R. Poprawe, "Applications of laser transmission processes for the joining of plastics, silicon and glass micro parts," Microsystem Technologies, vol. 14, no. 12, pp. 1879-1886, 2008.

[3] V. Wippo, M. Devrient, M. Kern et al., "Evaluation of a pyrometric -based temperature measuring process for the laser transmission welding," Physics Procedia, vol. 39, pp. 128-136, 2012.

[4] B. Acherjee, A. S. Kuar, S. Mitra, D. Misra, and S. Acharyya, "Experimental investigation on laser transmission welding of PMMA to ABS via response surface modeling," Optics \& Laser Technology, vol. 44, no. 5, pp. 1372-1383, 2012.

[5] E. Haberstroh, W.-M. Hoffmann, R. Poprawe, and F. Sari, "Laser transmission joining in microtechnology," Microsystem Technologies, vol. 12, no. 12, p. 1173, 2006.

[6] S. T. Yang, W. S. Hwang, and T. W. Shyr, "Reverse transformation from $\alpha$ to $\gamma$ in lightly and heavily cold-drawn austenitic stainless steel fibers," Metals and Materials International, vol. 19, no. 6, pp. 1181-1185, 2013.

[7] S. Perrin, L. Marchetti, C. Duhamel, M. Sennour, and F. Jomard, "Influence of irradiation on the oxide film formed on $316 \mathrm{~L}$ stainless steel in PWR primary water," Oxidation of Metals, vol. 80, no. 5-6, pp. 623-633, 2013.

[8] R. de Sousa Camposinhos, "Stainless steel and aluminium anchors," in Stone Cladding Engineering, pp. 155-167, Springer, Amsterdam, The Netherlands, 2014.

[9] X. Wang, H. Chen, H. Liu et al., "Simulation and optimization of continuous laser transmission welding between PET and titanium through FEM, RSM, GA and experiments," Optics and Lasers in Engineering, vol. 51, no. 11, pp. 1245-1254, 2013.

[10] G. Coman and G. Bahrim, "Optimization of xylanase production by Streptomyces sp. P12-137 using response surface methodology and central composite design," Annals of Microbiology, vol. 61, no. 4, pp. 773-779, 2011.
[11] M. Demirel and B. Kayan, "Application of response surface methodology and central composite design for the optimization of textile dye degradation by wet air oxidation," Demirel and Kayan International Journal of Industrial Chemistry, vol. 3, no. 24, pp. 1-10, 2012.

[12] Y. C. Lin, C. C. Tsao, C. Y. Hsu, S. K. Hung, and D. C. Wen, "Evaluation of the characteristics of the microelectrical discharge machining process using response surface methodology based on the central composite design," International Journal of Advanced Manufacturing Technology, vol. 62, no. 9-12, pp. 10131023, 2012.

[13] S. Sugashini and K. M. M. S. Begum, "Optimization using central composite design (CCD) for the biosorption of $\mathrm{Cr}(\mathrm{VI})$ ions by cross linked chitosan carbonized rice husk (CCACR)," Clean Technologies and Environmental Policy, vol. 15, no. 2, pp. 293-302, 2013.

[14] X. Wang, X. Song, M. Jiang et al., "Modeling and optimization of laser transmission joining process between PET and 316L stainless steel using response surface methodology," Optics and Laser Technology, vol. 44, no. 3, pp. 656-663, 2012. 

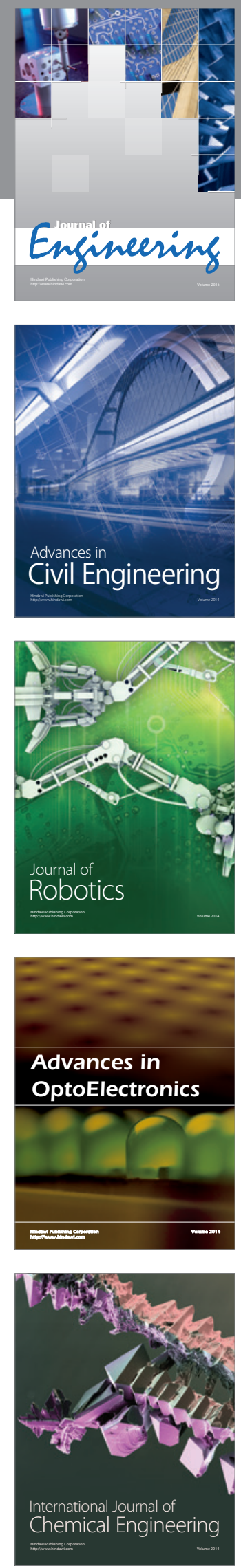

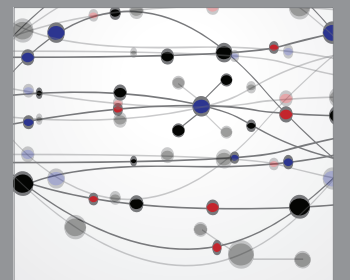

The Scientific World Journal
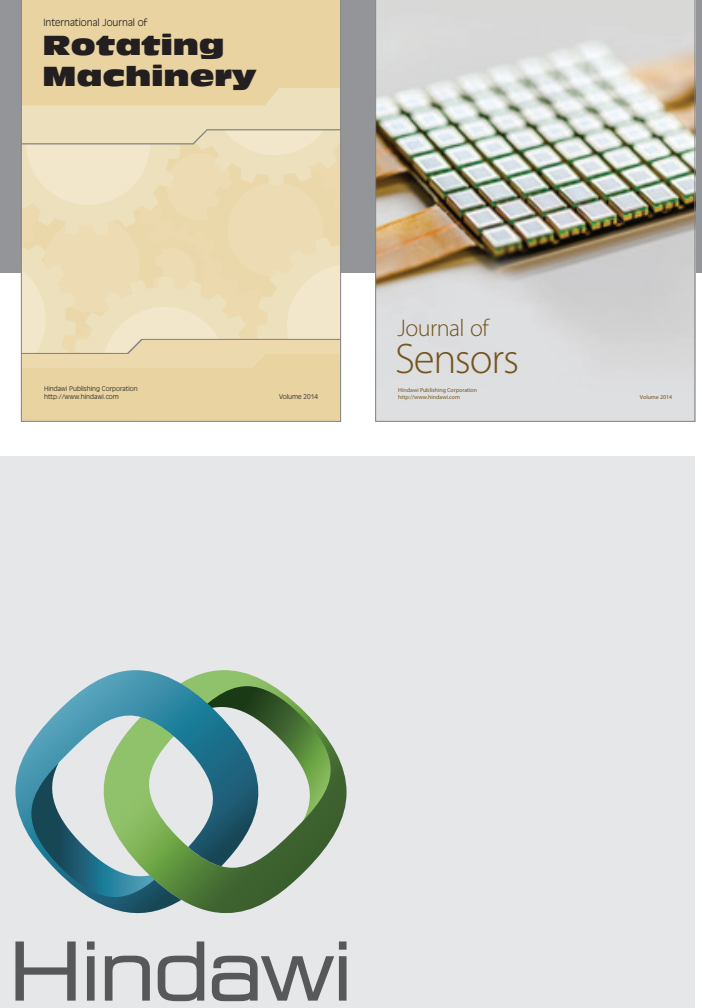

Submit your manuscripts at http://www.hindawi.com
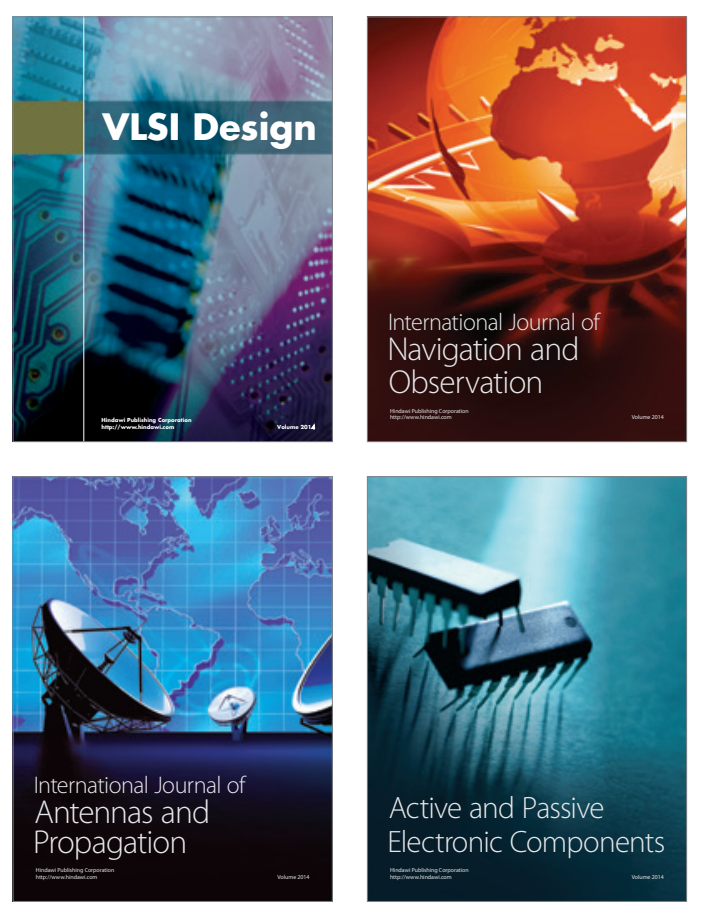
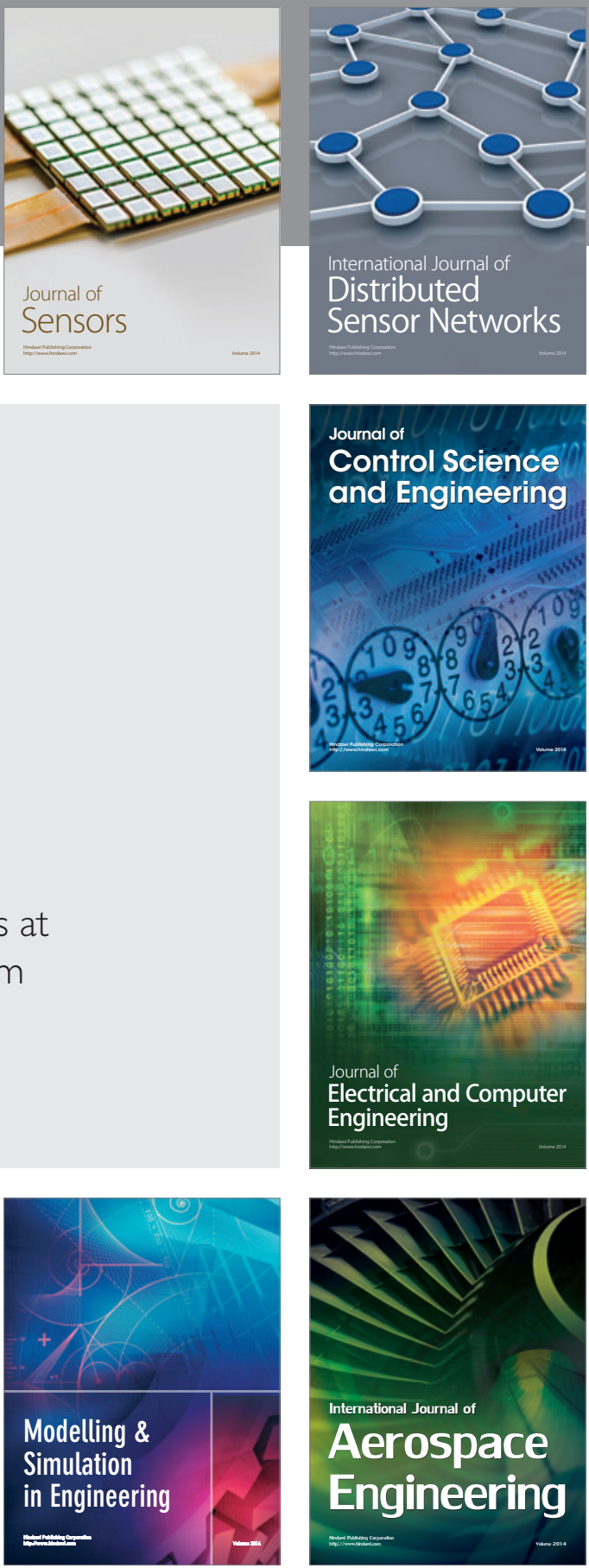

Journal of

Control Science

and Engineering
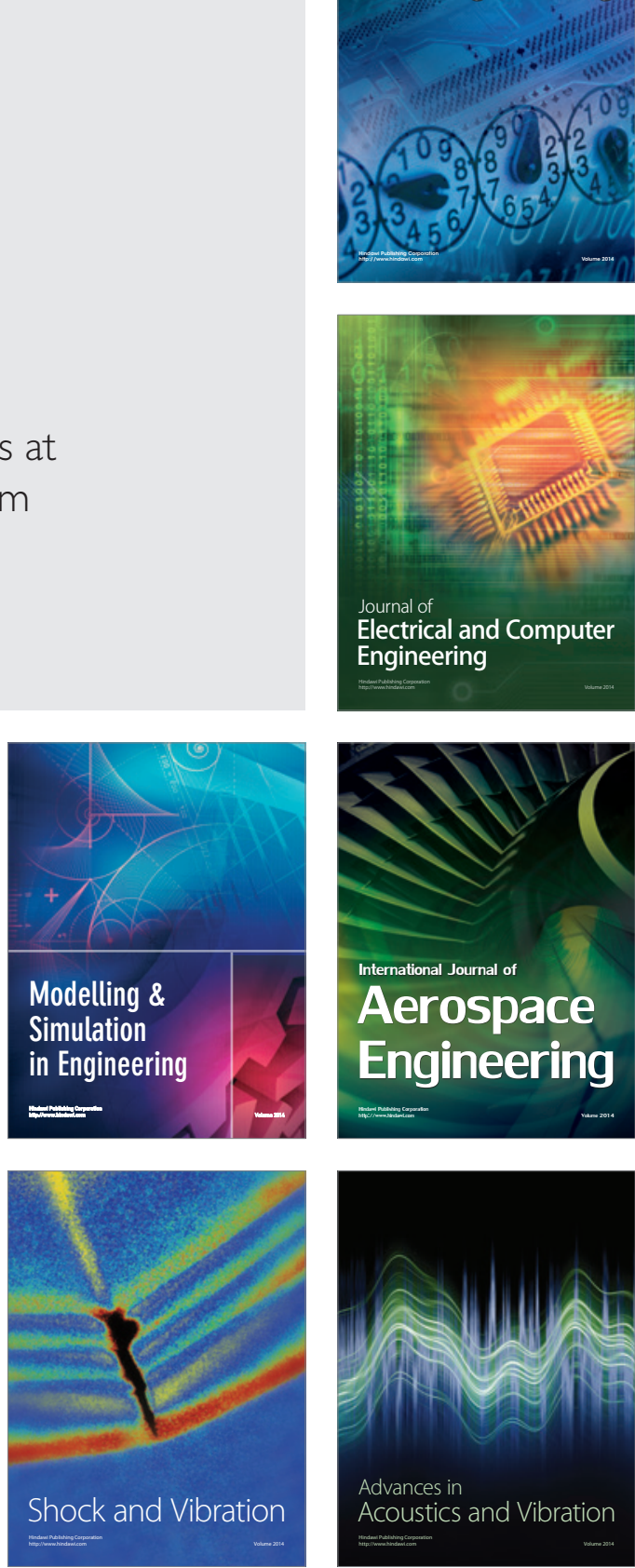